\title{
Autobiografia e representação de si mesmo: Graciliano segundo Graciliano
}

\section{Autobiography and representation of self: Graciliano according to Graciliano}

\author{
Márcia Vescovi Fortunato é doutora em Educação pela \\ Universidade de São Paulo (USP) e coordenadora do curso de Pós- \\ Graduação Lato Sensu "Formação de Escritores e Especialistas \\ em Produção de Textos Literários", do Instituto Superior de \\ Educação Vera Cruz (ISE Cevec).
}

Contato: mvfortunato@ig.com.br

\section{Resumo}

A partir da leitura de Infância, de Graciliano Ramos, este artigo reflete sobre o modo como o autor se faz representar em sua autobiografia, seja como autor-criador que assume uma posição discursiva a partir da qual enuncia fatos rememorados, seja como objeto do discurso autobiográfico, ao narrar a própria vida e representar a si mesmo como protagonista de sua narrativa.

Palavras-chave: autobiografia; representação de si mesmo; autoria.

\section{Abstract}

From the reading of Graciliano Ramos's Infância, this article reflects upon how the author represents himself in his autobiography, whether as the author-creator who assumes a discursive position from which he enunciates the experienced facts as recalled from memory, or as the object of the autobiographic discourse, in narrating his own life and representing himself as the protagonist of his narrative.

Keywords: autobiography; representation of self; authorship. 


\section{Autobiografia: reinvenção do real}

Escrito depois de Caetés (1933), São Bernardo (1934), Angústia (1936) e Vidas secas (1938), Infância (1945) foi o livro em que Graciliano Ramos estreou como memorialista. Nele, o autor relata suas lembranças da vida de menino.

Nascido em 27 de outubro de 1892, em Quebrangulo, Alagoas, Graciliano foi o primeiro de dezesseis filhos. Suas primeiras recordações remontam aos seus 2 ou 3 anos, e eram um tanto vagas: um vaso de louça cheio de pitombas, uma vasta sala, um pátio, árvores enormes carregadas de pitombas - ou laranjas? Para o menino, tudo que era esférico eram pitombas. Esse era o cenário de uma escola em que sua família pernoitou em 1895, quando estava de mudança para a Fazenda Pintadinho, em Buíque, no sertão de Pernambuco.

Desde muito pequeno, Graciliano foi tratado pelos pais com disciplina rigorosa. A percepção que guardou dessa época é assim relatada em Infância:

Meu pai e minha mãe conservavam-se grandes, temerosos, incógnitos. Revejo pedaços deles, rugas, olhos raivosos, bocas irritadas e sem lábios, mãos grossas e calosas, finas e leves, transparentes. Ouço pancadas, tiros, pragas, tilintar de esporas, batecum de sapatões no tijolo gasto. Retalhos e sons dispersavam-se. Medo. Foi o medo que me orientou nos primeiros anos, pavor (Ramos, 1998, p. 11-12).

Muitas vezes foi castigado corporalmente e nutria forte sentimento de injustiça não só pelo que lhe acontecia, mas também pelo que ocorria a outros, os mais fracos, os que, como ele, careciam de poder de defesa contra os que se impunham pela força. 0 capítulo 0 cinturão é emblemático desse sentimento. Nele, Graciliano relata seu sofrimento e os traumas que lhe restaram devido à punição imputada pelo pai, que o acusava de ter perdido um cinturão, descoberto, por fim, em meio aos panos da rede em que o próprio pai dormira.

Ainda na Vila Buíque, teve sua primeira experiência de aprendizagem da escrita. Graciliano vivia em um ambiente letrado e, embora a cultura familiar fosse rudimentar, sua mãe, vez ou outra, lia para ele. Graciliano deixa entrever, entretanto, em Infância, que desde sua meninice era criativo, curioso e questionador - o que muitas vezes deixava seus pais em situação difícil. Durante uma leitura de livros religiosos que chegavam à família pelo correio, sua mãe agitou-se ao ler que se aproximava 
o fim do mundo com a chegada de um cometa exatamente na passagem para o século XX. Graciliano comentou:

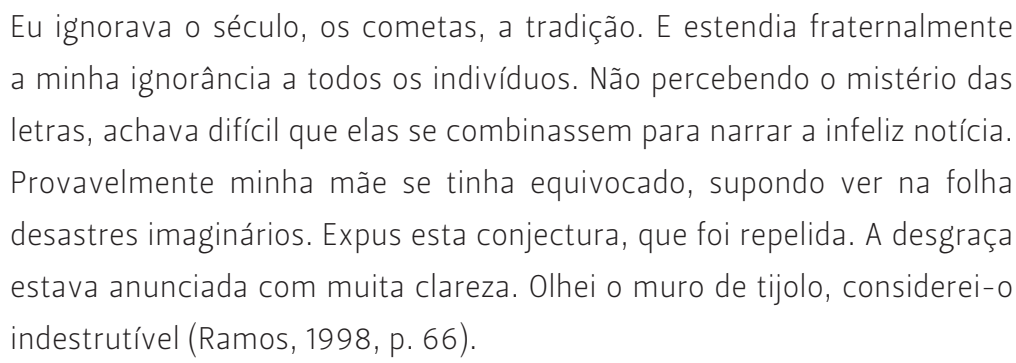

Essa inquietação produzia comportamentos inaceitáveis para seus pais. Por isso os castigos. Por isso sua dificuldade para a alfabetização. Os métodos de ensino eram muito autoritários e a não compreensão do sentido da construção escrita foi, provavelmente, a razão de tanta dificuldade e de tanto suplício, como ele próprio relatou no capítulo Leitura. 0 fracasso na aprendizagem era um reforço muito grande para sua autodepreciação, principalmente, talvez, pelo efeito que produzia em seu pai, ou pelo medo que Graciliano nutria pela reação que ele poderia ter.

Vencidos os primeiros desafios, o menino descobriu o prazer de ler. Já morava em Viçosa, para onde a família se havia mudado em 1899. Jerônimo Barreto, um tabelião que possuía uma biblioteca com muitos livros, alimentava a leitura de Graciliano. Enquanto em 1902 Euclides da Cunha publicava Os sertões, Graciliano se envolvia com José de Alencar, Joaquim Manoel de Macedo e Júlio Verne. Essa foi uma experiência fundamental em sua vida:

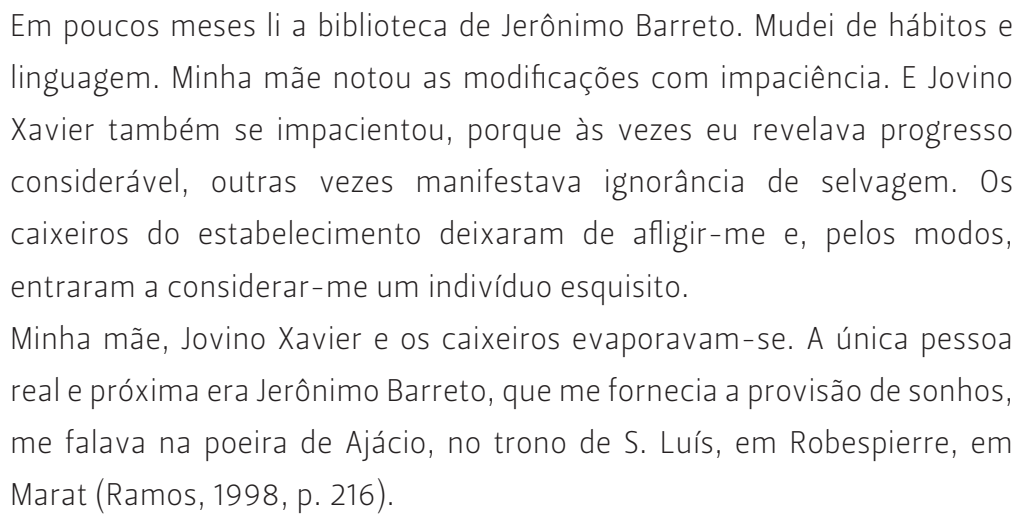

E logo nasceu o escritor. Graciliano publicou pela primeira vez em 1904, n'O dilúculo, jornal do Internato Alagoano, de Viçosa, onde estudava. Tratava-se de um conto, chamado Pequeno Pedinte. Graciliano tinha então 11 anos. 
Esse é o Graciliano que, em linhas gerais, pode-se ler em Infância, autobiografia que termina, como era de se esperar, com a entrada de Graciliano na puberdade.

Dos dois livros de memórias que Graciliano Ramos escreveu, Infância (1945) e Memórias do cárcere (1953), o primeiro "é autobiografia tratada literariamente; a sua técnica expositiva, a própria língua parecem indicar o desejo de lhe dar consistência de ficção". O segundo, "é depoimento direto e, embora grande literatura, muito distante da tonalidade propriamente criadora" (Candido, 1992, p. 63-64).

Essa distinção de Antônio Candido é interessante porque atribui ao acabamento estético do texto sua qualidade literária. Segundo tal critério, fazer literatura é produzir um texto esteticamente acabado. Esse procedimento de autoria, entretanto, está submetido a certas restrições. 0 tratamento de linguagem dado a qualquer texto se submete tanto à formação discursiva (Foucault, 2002) do autor quanto às restrições do gênero do discurso, que são definidas pelo uso que se faz socialmente do texto. Considerando essas restrições à autoria, como o autor se faz representar em sua autobiografia? A partir de que escolhas? E o que determina essas decisões? Passemos, então, ao exame dessas questões.

Em todo discurso há um sujeito que se constitui para dizer algo. 0 sujeito não é o autor real, mas

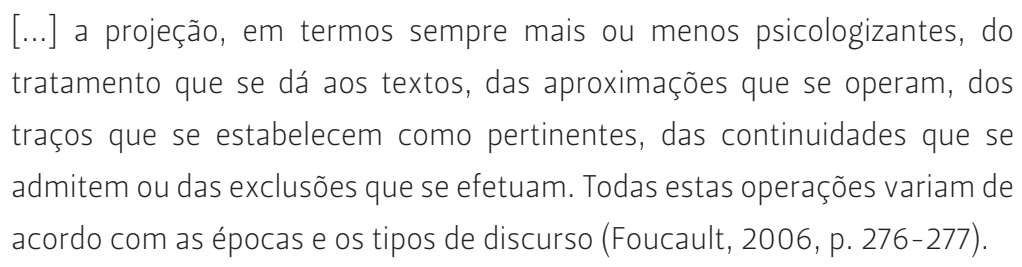

0 autor é, assim, uma posição discursiva que representa aquele que fala, uma imagem que se projeta para dar voz a determinado conteúdo. Pode ser em maior ou menor grau uma representação do autor real, pessoa física que redige o discurso. Cada discurso tem um contexto de produção e difere de qualquer outro, quer pela sua materialidade, quer pelo conteúdo que expressa. Difere mais ainda porque, em cada texto, o sujeito que nos fala emerge de forma singular.

A construção dessa singularidade pode ser mais bem compreendida no âmbito do processo de criação literária e do conceito de autoria proposto por Bakhtin em diversos momentos de sua obra. Em 0 problema do conteúdo, do material e da forma 
na criação literária, de 1924, Bakhtin (2002) já pensava que o autor, em seu processo de criação, exerce a função de inventor ativo do objeto como autor-criador. Neste caso, ele é elemento da obra, diferentemente do autor real (ou autor-pessoa), que é elemento do acontecimento ético e social da vida. 0 produto gerado por essa intervenção do autor é resultado de escolhas sígnicas, cognitivas e éticas, de modo que o autor concentra em seu gesto construtor todas as possibilidades de vir-a-ser da obra. Assim, a obra se constitui por meio do autor e vice-versa, uma vez que o autor-criador deixa na obra um rastro de si e se torna um elemento constitutivo de sua forma artística. A obra em sua materialidade estética é, em relação ao autor, seu meio e seu fim.

Embora aceite a possibilidade de a obra refratar a visão de mundo do autor, Bakhtin (2003a) não admite a comparação meramente factual que confunda o autor-criador com o autor real, pois isso demonstra a incompreensão do princípio criador da relação do autor com a personagem. Essa distinção entre autor-criador e autor real é uma proposição recorrente em Bakhtin, apresentada em diversas ocasiões: no ensaio 0 autor e a personagem na atividade estética (2003a), escrito na década de 1920, em seu estudo sobre Dostoiévski (2005) e posteriormente em suas notas de 1959-1961, quando aborda questões relativas ao texto (2003b).

\footnotetext{
[...] todo enunciado tem uma espécie de autor, que no próprio enunciado escutamos como o seu criador. Podemos não saber absolutamente nada sobre o autor real, como ele existe fora do enunciado. As formas dessa autoria real podem ser muito diversas. Uma obra qualquer pode ser produto de um trabalho em equipe, pode ser interpretada como trabalho hereditário de várias gerações, etc., e apesar de tudo, sentimos nela uma vontade criativa única, uma posição determinada diante da qual se pode reagir dialogicamente. A reação dialógica personifica toda enunciação à qual ela reage (Bakhtin, 2005, p. 184).
}

0 autor-criador é uma das faces do autor real, pessoa física que se expressa de um modo ou de outro sob a imagem de autor que criou. Nesse sentido, tal autor representado ocupa uma posição determinada no discurso, dirige a cena e reage dialogicamente aos personagens e às situações enquanto os cria. Para Bakhtin, o leitor do enunciado percebe apenas o autor-criador. É por meio deste que o autor real se manifesta. Portanto, o autor-criador é uma possibilidade, um devir do autor real. Do ponto de vista discursivo, o autor-criador concebido por Bakhtin pode ser compreendido como o sujeito constituído no e pelo discurso e que ocupa uma posição dialógica singular na interlocução que estabelece com 
outros interlocutores por meio da atividade discursiva que realiza.

De modo geral, há variações de um mesmo gênero que podem alterar significativamente o teor do que se pretende comunicar. Essas alterações têm origens diversas. Elas podem, por exemplo, resultar de mudanças ocorridas no uso da língua ao longo do tempo, determinadas pelo surgimento de novas práticas de comunicação social. Além disso, elas podem ocorrer também num mesmo momento histórico, na medida em que surjam diferentes mídias sugerindo diferentes usos de um mesmo gênero discursivo, com alterações determinadas pelo suporte em uso.

Marcuschi (2008), considerando o suporte como "locus físico ou virtual com formato específico que serve de base ou ambiente de fixação do gênero materializado como texto" (p. 174), observa que o gênero não fica indiferente ao suporte, uma vez que ele nunca é neutro e é sempre marcado por convenções de uso e pela especificidade de seus formatos e de suas funções. Essa seria uma explicação possível para a variação de gênero existente, por exemplo, entre as memórias relatadas em Infância e o relato autobiográfico breve, sucinto e direto que Graciliano escreveu para publicação no semanário Casmurro, em 1939, jornal carioca que tinha uma coluna intitulada Vamos ler, citado por Silveira (1998, p. 278-279). É muito provável que o primeiro, publicado em livro, e o segundo, em jornal, tenham recebido tratamentos diferentes por parte do autor, já que variaram as condições de produção e recepção dos textos, os formatos e as expectativas de comunicação criadas por cada suporte.

Segundo análise de Candido (1992), há autobiografias que tendem mais à objetividade e recebem um tratamento informativo, e, assim, podem imprimir no leitor mais credibilidade, causando a impressão de que apresentam os fatos tal como aconteceram. São confissões. Por outro lado, há aquelas que recebem um tratamento mais literário e podem ser lidas como ficção: os fatos parecem verossímeis, mas não necessária ou inteiramente verdadeiros, ainda que originados no real. Ficamos, nesse sentido, entre a confissão e a ficção. Portanto, uma autobiografia pode ser compreendida como um gênero literário ou não. Situase, a exemplo dos gêneros híbridos tais como a crônica, entre documento e ficção, já que circula tanto na esfera literária quanto na esfera dos documentos históricos. É exatamente essa característica que nos interessa para a reflexão da relação entre o real e sua representação.

Receba tratamento literário ou não, toda autobiografia se 
refere simbolicamente ao real sem se confundir com ele. Assim, o problema retórico proposto para o autor na produção de uma autobiografia é a representação de si mesmo por meio da narrativa de fatos reais, na qual o autor-personagem se constitui como protagonista.

É então que um jogo interessante de autoria se estabelece: o autor real se posiciona como autor-criador - aquele que se projeta no texto ao narrar, refratando, de certa forma, o autor real, com o propósito de recompor sua memória de fatos vividos. Por meio destes, o próprio autor se constitui, agora revestido pela figura do autor-personagem. 0 autor é, assim, agente e protagonista de seu discurso.

Esse processo de representação em que o autor real se envolve - projetando a si próprio como narrador (autor-criador) e como aquele sobre quem fala (o autor-personagem) - é afetado pelo contexto de produção em que se encontra o autor real. Na medida em que cabe ao autor-criador assumir a posição a partir da qual o autor-personagem será lido, já que se trata de um discurso em primeira pessoa, essas duas representações de si mesmo se sobrepõem. Desse modo, ainda que o autor-criador tivesse o propósito de apreender a totalidade do vivido, estaria afetado pela posição discursiva ocupada por ele e determinada pelo contexto de produção - o gênero, o suporte, o leitor e os objetivos que orientam suas decisões durante o processo de produção do texto.

Sabemos que mesmo as recordações mais claras e mais detalhadas não passam de fragmentos do que foi vivido. Nossa memória recupera apenas partes dos acontecimentos: gestos, frases, sensações, impressões que nos marcaram e que produziram o significado que deles nos ficam. Além disso, na maioria das vezes, esses fragmentos de memória não nos afloram de modo sequencial, mas eles nos acorrem por associação, sem uma sintaxe fixa, pré-determinada. No momento em que nos reportamos a alguém para narrar o que recordamos, organizamos os fatos e transformamos nossa memória em discurso. "Quando recordamos, ampliamos determinados acontecimentos e então os reinterpretamos à luz da experiência subsequente e da necessidade presente" (Lowenthal, 1998, p. 97).

Graciliano confirma:

Naquele tempo a escuridão se ia dissipando, vagarosa. Acordei, reuni pedaços de pessoas e de coisas, pedaços de mim mesmo que boiavam no passado confuso, articulei tudo, criei o meu pequeno mundo incongruente. 
Às vezes as peças se deslocavam - e surgiam estranhas mudanças. Os objetos se tornavam irreconhecíveis, e a humanidade, feita de indivíduos que me atormentavam e indivíduos que não me atormentavam, perdia os característicos (Ramos, 1998, p. 17).

Para Candido (1992), "a autobiografia foi um caminho que [Graciliano Ramos] escolheu e para o qual passou naturalmente, quando a ficção já não lhe bastava para exprimir-se" (p. 66).

Observamos, assim, um caso em que a escrita funciona como ferramenta de questionamento e reflexão em busca de explicação para si próprio e para o mundo. Graciliano,

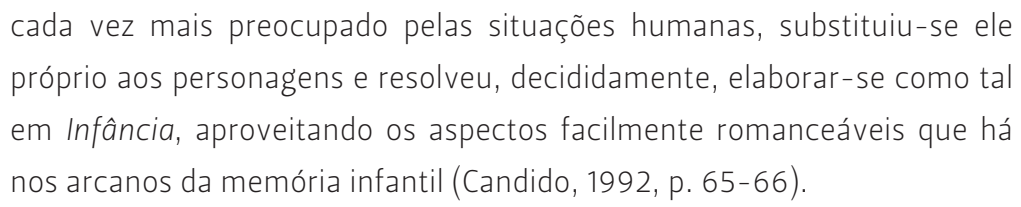

cada vez mais preocupado pelas situações humanas, substituiu-se ele próprio aos personagens e resolveu, decididamente, elaborar-se como tal em Infância, aproveitando os aspectos facilmente romanceáveis que há nos arcanos da memória infantil (Candido, 1992, p. 65-66).

Talvez tenha sido estratégia de Graciliano romancear sua infância para criar uma interface estética e, assim, apresentar-se ao leitor. Tratar-se-ia, desse modo, de uma estratégia de autoria.

\section{As possibilidades de representação de si mesmo}

Para refletir a respeito da natureza da autobiografia e das possibilidades de o autor se representar como tema de seu discurso, pode-se recorrer a outro texto autobiográfico de Graciliano Ramos:

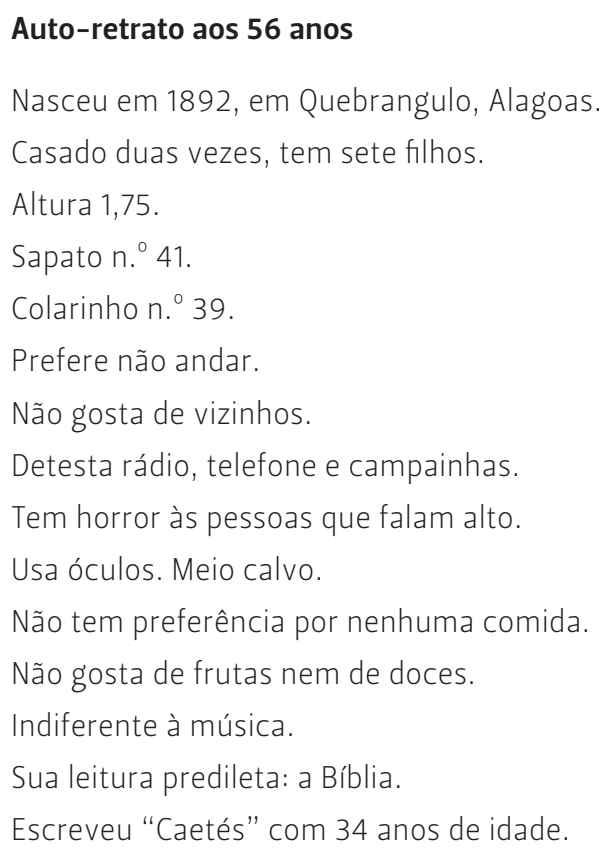


Não dá preferência a nenhum dos seus livros publicados.

Gosta de beber aguardente.

É ateu. Indiferente à Academia.

Odeia a burguesia. Adora crianças.

Romancistas brasileiros que mais Ihe agradam: Manoel Antônio de Almeida, Machado de Assis, Jorge Amado, José Lins do Rego e Rachel de Queiroz.

Gosta de palavrões escritos e falados.

Deseja a morte do capitalismo.

Escreveu seus livros pela manhã.

Fuma cigarros "Selma" (três maços por dia).

É inspetor de ensino, trabalha no "Correio da Manhã".

Apesar de o acharem pessimista, discorda de tudo.

Só tem cinco ternos de roupa, estragados.

Refaz seus romances várias vezes.

Esteve preso duas vezes.

É-Ihe indiferente estar preso ou solto.

Escreve à mão.

Seus maiores amigos: Capitão Lobo, Cubano, José Lins do Rego e José Olympio.

Tem poucas dívidas.

Quando prefeito de uma cidade do interior, soltava os presos para construírem estradas.

Espera morrer com 57 anos. (Ramos, [1948?])

Crítico e, por vezes, irreverente, o discurso do Auto-retrato aos 56 anos, composto em terceira pessoa, é dito por um sujeito que trata de si mesmo à distância, como se falasse de outro. Esse autorretrato é, como o próprio nome diz, uma descrição; fundase, contudo, na negação ("não gosta", "tem horror", "detesta", "indiferente", "odeia", "discorda"). É marcado, além disso, por acontecimentos que delimitam sua atividade ao longo do tempo e resumem sua trajetória: nasceu, casou duas vezes, escreveu livros e os reescreveu várias vezes, foi inspetor de ensino, esteve preso duas vezes, foi prefeito, espera morrer.

Auto-retrato aos 56 anos é um texto poético. É constituído por enunciados curtos que se sucedem como uma lista, cujo propósito parece ser o de buscar uma forma objetiva e sucinta de reunir as características mais significativas de um Graciliano adulto. Nesse sentido é metonímico: constrói o personagem verso a verso, por meio de fragmentos de acontecimentos que marcaram sua vida. Um conjunto de observações que, evidentemente, não abarca a vida do homem, mas nos dá pistas para descobrir o que Graciliano pensava a respeito de si próprio, ou o que ele gostaria que pensássemos sobre sua visão de si mesmo. Sucinto, reservado e duro na avaliação de si. 
Muito diferente é o sujeito de Infância, que fala do menino Graciliano com ternura, simpatia e, às vezes, com consternação, um sujeito que pondera e revê as percepções do menino, como que em busca de restabelecer a verdade do que viveu. É possível perceber esse sujeito narrador reflexivo, ponderado, quando se observam, por exemplo, dois momentos de caracterização da mãe. 0 primeiro, sob a perspectiva do menino:

\begin{abstract}
Nesse tempo meu pai e minha mãe estavam caracterizados: [...] uma senhora enfezada, agressiva, ranzinza, sempre a mexer-se, bossas na cabeça mal protegida por um cabelinho ralo, boca má, olhos maus que em momentos de cólera se inflamavam com um brilho de loucura (Ramos, 1998, p. 13).
\end{abstract}

0 segundo, uma reavaliação do sujeito narrador, que justifica, de certo modo, as atitudes da mãe, atribuindo seu sofrimento à aventura extraconjugal do pai que resultou em uma irmã natural, que vivia na mesma casa e cuja presença estava o tempo todo a lembrar do acontecido:
Se não existisse aquele pecado, estou certo de que minha mãe teria sido mais humana. De fato meu pai comportava-se bem. Mas havia aquela evidência de faltas antigas, uma evidência forte, de cabeleira negra, beiços vermelhos, olhos provocadores. [...] [Ela] maltratava-se maltratando-nos (Ramos, 1998, p. 21).

Esses distintos "Gracilianos" que emergem do discurso como sujeitos singulares são projeções distintas que o autor real faz de si próprio e que dialogam entre si, revendo e reavaliando os fatos rememorados da infância.

A representação de si mesmo em Infância mostra que a cultura familiar em que ele cresceu valorizava a obediência, a maior atenção ao sentimento do outro do que aos próprios, o respeito ao código moral, ou seja, valorizava a representação de um si mesmo interdependente (Leme, 2004, p. 119). Ocorre que Graciliano reconheceu outros valores nas atitudes do pai: 
considerava-os duvidosos. Talvez até admitisse o Barão de Ladário como personagem de ficção (Ramos, 1998, p. 48).

A descrição de Graciliano deixa entrever o pai como um homem com pensamento autônomo e questionador, apesar da limitação intelectual ("Tinha às vezes, porém, ideias próprias", "era bastante incrédulo", "desconfiava dos livros"). São atitudes e valores que Graciliano aprendeu, embora a educação que o pai deliberadamente dava ao filho estivesse calcada em premissas muito diferentes.

Outras foram as aprendizagens de Graciliano. Por meio da leitura desenvolveu suas capacidades intelectuais, o pensamento reflexivo e criativo, além de suas habilidades de leitura e produção escrita. Nesse sentido, podemos dizer que a linguagem possibilitou uma interação importantíssima para o autor: funcionou como ferramenta de autoanálise e de reflexão sobre si mesmo e o mundo.

Vygotsky atribuiu à linguagem importante função na definição das singularidades de pensamento. Segundo Veer e Valsiner (1996), para Luria e Vygotsky,
[...] o domínio dos meios culturais irá transformar nossa mente: uma criança que tenha dominado o instrumento cultural da linguagem nunca mais será a mesma criança outra vez [...] pessoas pertencentes a culturas variadas pensariam, literalmente, de maneiras diferentes, e a diferença não estava confinada ao conteúdo do pensamento mais incluía também as maneiras de pensar (Veer; Valsiner, 1996, p. 247).

Por isso é possível dizer que a literatura teve forte significado para a vida de Graciliano Ramos: seja como ferramenta de busca de identidade e necessidade de elaboração de si mesmo, seja como forma de interagir no mundo.

Graciliano tinha claro o valor da linguagem e prescrevia seu uso. Segundo Silveira, este foi seu diálogo com o escritor:

\footnotetext{
- Deve-se escrever da mesma maneira como as lavadeiras lá de Alagoas fazem seu ofício. Sabe como elas fazem?

- Não.

- Elas começam com uma primeira lavada, molham a roupa suja na beira da lagoa ou do riacho, torcem o pano, molham-no novamente, voltam a torcer. Depois colocam o anil, ensaboam e torcem uma, duas vezes. Depois enxáguam, dão mais uma molhada, agora jogando a água com a mão. Depois batem o pano na laje ou na pedra limpa, e dão mais uma torcida e mais outra, torcem até não pingar do pano uma só gota. Somente depois
} 
de feito tudo isso é que elas dependuram a roupa lavada na corda ou no varal, para secar. Pois quem se mete a escrever devia fazer a mesma coisa. A palavra não foi feita para enfeitar, brilhar como ouro falso; a palavra foi feita para dizer (Silveira, 1998, p. 284).

Infância disse. Porém, falar de si mesmo, ao contrário de ser um gesto simples e natural, implica uma série de desafios, principalmente do ponto de vista de como se dá a representação de si mesmo no discurso.

Nem tudo o que é relatado nos textos autobiográficos é passível de comprovação, mas não se pode dizer que o que se diz não é exato ou verdadeiro. É o exato e a verdade de cada sujeito, porque o indivíduo se transforma, a cada momento - e em cada discurso sabe-se diferente.

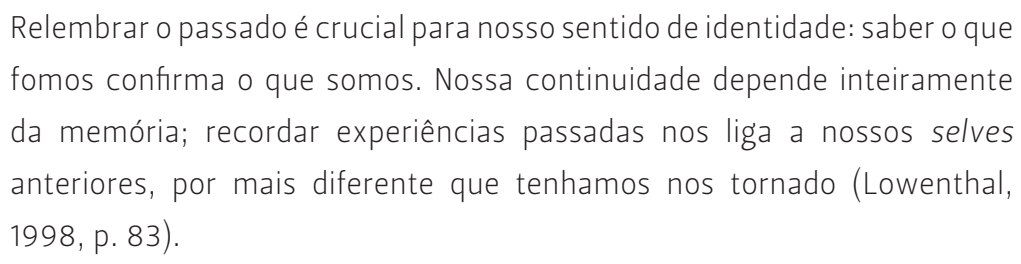

Conforme a vida se desenrola, as condições culturais a que todos estamos submetidos se modificam e atuam sobre nós, alterando nossas identidades. Por isso, ao longo do tempo, cada um de nós tem diferentes representações de si mesmo.

Por outro lado, escrever uma autobiografia é transpor uma representação de si mesmo para o papel. 0 autor produz, assim, um artefato de memória que será distinto das possíveis autobiografias anteriores. Além da transitoriedade da representação de si mesmo, em cada escritura vai existir um sujeito que fala de um lugar diferente, já que esse sujeito também está submetido a circunscritores culturais (Silva; Rosseti-Ferreira; Carvalho, 2004). É o que podemos observar em Infância e em Auto-retrato aos 56 anos. São distintos os sujeitos que formulam cada discurso e que selecionam seus fragmentos de memória, os quais se convertem na matriz semântica (Bruner; Weisser, 1997) que oferece contexto àqueles sujeitos e confere materialidade ao discurso. 
mas depende dos atos da conceitualização: a criação de esquemas de interpretação pelos quais a memória semântica dá coerência aos elementos da memória episódica. A esquematização é comandada por regras de gênero e convenção cultural, que, por sua vez, impõe regras de uso linguístico e construção narrativa. Por fim, em virtude de sua função como 'artifício locacional', a autobiografia cria a necessidade de identificação e individualização, satisfazendo, ao mesmo tempo, essas necessidades se conseguir atingir a "correção" de representação (Bruner; Weisser, 1997, p. 149).

É desse discurso articulado a partir dos fragmentos de memória que o leitor toma conhecimento. Essa articulação supõe um autor real que recria a si próprio duplamente, como sujeito discursivo (autor-criador que ocupa uma posição a partir da qual fala) e objeto discursivo (sobre quem se fala).

\section{Considerações finais}

A partir das considerações anteriores, é possível compreender que o autor de uma autobiografia é sempre uma figura do discurso por ele produzido. Desse modo, ele ocupa um lugar definido como sujeito que relata as informações que retém na memória ou as representações que delas elabora. Nesse sentido, a singularidade do indivíduo não está propriamente no que ele é ou em suas ações, mas no discurso que profere sobre si mesmo, seja de forma direta (nas autobiografias) ou de forma indireta (nos textos em que, falando sobre o outro ou sobre o mundo, deixa entrever a si mesmo, como o autor-criador).

0 arranjo formal do texto vai, então, interferir enormemente em sua recepção, na leitura das vidas narradas. Isso se dá porque o que está escrito não é o vivido, mas uma versão linguística dos pensamentos, sentimentos, fatos e de tudo o que compõe, na visão do autor, naquele momento, uma representação possível de sua vida e de si próprio. Portanto, ao lermos Infância ou Auto-retrato aos 56 anos, o Graciliano a que temos acesso é uma representação possível do menino Graciliano segundo outro Graciliano, o autorcriador a que temos acesso por meio do discurso.

A escrita parece funcionar, para Graciliano, como ferramenta de questionamento e reflexão em busca de explicação para si próprio e para o mundo que o rodeia. Ao se contrapor às injustiças sociais de que a cena do cinturão do pai é emblema, Graciliano nega os valores da sociedade e as normas deles decorrentes. A lucidez e o equilíbrio presentes na manipulação controlada das situações que cria na ficção (São Bernardo, Vidas secas) parecem demonstração de poder daquele que em Infância esteve sempre indefeso, sob o jugo de um pai injusto e opressor. 


\section{REFERÊNCIAS}

BAKHTIN, Mikhail. O problema do conteúdo, do material e da forma na criação literária. In: Questões de literatura e de estética: a teoria do romance. Tradução de Aurora Fornoni Bernardini et al. 5. ed. São Paulo: Hucitec, 2002. p. $13-70$.

O autor e a personagem na atividade estética.

In: _. Estética da criação verbal. Tradução de Paulo Bezerra. São Paulo: Martins Fontes, 2003a. p. 3-192.

O problema do texto na lingüística, na filologia e em outras ciências humanas. In: Estética da criação verbal. Tradução de Paulo Bezerra. São Paulo: Martins Fontes, 2003b. p. 307-335.

Problemas da poética de Dostoiévski. Tradução de Paulo Bezerra. Rio de Janeiro: Forense Universitária, 2005.

BRUNER, Jerome; WEISSER, Susan. A invenção do ser: a autobiografia e suas formas. In: OLSON, David; TORRANCE, Nancy. Cultura escrita e oralidade. São Paulo: Ática, 1997.

CANDIDO, Antonio. Ficção e confissão. São Paulo: Editora 34, 1992.

FOUCAULT, Michel. A arqueologia do saber. Tradução de Luiz Felipe Baeta Neves. 6. ed. Rio de Janeiro: Forense Universitária, 2002.

O que é um autor? In: Estética: literatura

e pintura, música e cinema. Organização e seleção de textos por Manoel Barros da Motta. Tradução de Inês Autran Dourado Barbosa. 2. ed. Rio de Janeiro: Forense Universitária, 2006. (Ditos e escritos, v. 3)

LEME, Maria Isabel da Silva. A construção do si mesmo cultural. In: SOUZA, Maria Thereza Costa Coelho de. Os sentidos de construção: o si mesmo e o mundo. São Paulo: Casa do Psicólogo, 2004.

LOWENTHAL, David. Como conhecemos o passado. Projeto História: Revista do Programa de Estudos de Pós-Graduação em História, São Paulo, v. 17, p. 63-201, nov. 1998. 
MARCUSCHI, Luiz Antônio. Produção textual, análise de gêneros e compreensão. São Paulo: Parábola, 2008.

RAMOS, Graciliano. Infância. Rio de Janeiro: Record, 1998.

Auto-retrato aos 56 anos. [1948?]. Disponível em:

<http://www.graciliano.com.br/grporelemesmo.html>.

Acesso em: 2 set. 2012

SILVA, Ana Paula Soares da; ROSSETI-FERREIRA, Maria Clotilde; CARVALHO Ana Maria Almeida. Circunscritores: limites e possibilidades no desenvolvimento. In: ROSSETIFERREIRA, Maria Clotilde et al. (Orgs.) Rede de significações e o estudo do desenvolvimento humano. São Paulo: Artmed, 2004.

SILVEIRA, Joel. Na fogueira: memórias. Rio de Janeiro: Mauad, 1998.

VEER, René van der; VALSINER, Jaan. Vygotsky: uma síntese. São Paulo: Unimarco; Loyola, 1996. 